\title{
The Study of Vorticity Distribution Law Inside the Oxy-fuel Furnace based on FDS Direct Numerical Simulation
}

\author{
Yongfu Wu ${ }^{1, a}{ }^{,}$Meng Feng ${ }^{1, b}$,Liangliang $\mathrm{Li}^{1, \mathrm{c}}$, Zhongxing Liu ${ }^{1, \mathrm{~d}}$ \\ ${ }^{1}$ School of Energy and Environment, Inner Mongolia University of Science and Technology, China \\ Inner Mongolia BaoTou, 014010 \\ awyf07@imust.cn, b827288750@qq.com, '892793281@qq.com, ${ }^{\mathrm{d}}$ liuzx2@126.com
}

\begin{abstract}
Key words: the oxy-fuel furnace; FDS; MILD combustion; swirl motion
Abstract. Carrying on numerical calculation for oxy-fuel furnace gas movement under different speeds spout by using FDS direct numerical simulation software module. And analyzing the influence of different nozzle gas velocity on the velocity field and vorticity field distribution in the furnace under the condition of oxy-fuel furnace. Researchs showed that the gas velocity of the nozzle is bigger , the maximum reflux length of gas formed in the furnace is longer. The numbers of vorticity generated in the furnace is more. It is more conducive for the spread of diffusion furnace gas. It has a certain guiding significance for the realization of the oxy-fuel diffusion combustion.
\end{abstract}

\section{Introduction}

In recent years, with the increasingly prominent problems of environmental pollution, how to improve the energy utilization ratio and reduce the emission of harmful products has become a major issue of concern in the world. The oxy-fuel combustion technology is a combustion energy-saving technology developed in modern times. At first, the application of this technology is to improve the oil recovery rate. By the mid 1990s,due to the pressure of the greenhouse effect, using the oxygen combustion technology to reduce emissions of $\mathrm{CO} 2$ has become the main purpose of the research ${ }^{[1]}$.At present, oxygen combustion technology in many countries have entered the construction phase of the project. Between 2008 and 2010, there are 8 sets of demonstration power plants put into operation in the world ${ }^{[2-3]}$.It is not the best methed which use $78 \%$ nitrogen and $1 \%$ argon to dilute the oxygen for combustion and heat transfer. Because the nitrogen is heated in the combustion process, in order to save fuel, the energy transmitted to the nitrogen must be recycled. The oxy-fuel combustion greatly reduces the heating ${ }^{[4]}$ of the gas and the flue gas. The oxy-fuel combustion greatly reduces on the heating[4] of the gas and the flue gas. So the research of the whole oxygen heating furnace has great significance for energy-saving and emission reduction.

At home and abroad, for the oxy-fuel combustion technology also has a different degree of research. Kim et $\mathrm{al}^{[5]}$ carried on experimental research for the oxygen combustion model burner and normal oxygen burner. The research object is mainly aimed at the combustion characteristics, flame structure and flame length. The results showed: with the increasing of fuel rate and oxygen rate, the flame length reduced in the burner of oxygen combustion model.(It is because the flame viscosity of the enhanced oxygen combustion disturbance is 1.2 to 1.5 times of the traditional combustion flame viscosity.)In Japan, they have been carried on many application experiments for the combustion of gas, oil and coal. The results showed: oxygen combustion of $23 \%$ oxygen content can save energy $10 \%$ to $25 \%$,oxygen combustion of $25 \%$ oxygen content saving energy $20 \%$ to $40 \%$;oxygen combustion of $27 \%$ oxygen content can save energy $30 \%$ to $50 \%{ }^{[6]}$.In Germany,they carried on Oxygen combustion experiment with $27 \%$ oxygen content in a horse shoe type regenerative furnace.The results showed:the rate of the melting increased by $56.2 \%$,the consumption of energy decreased by $20 \%$,the temperature of the melting increased by 100 degrees Celsius ${ }^{[7]}$.Huang Xiaohong $^{[8]}$ et al. researched on oxygen combustion of pulverized coal in a plane flame carrying flow reaction system simulator.The research object is mainly aimed at the characteristics of the combustion flame. The results showed:under oxygen combustion mode,the flame length and volume are smaller than the traditional combustion mode.And the moisture has a significant influence on 
the flame characteristics of the pulverized coal combustion.Wu Yue ${ }^{[9]}$ et al.studied on oxygen combustion of pulverized coal.The research object is mainly aimed at the ignition temperature, burnout temperature and apparent activation energy.The results showed:under oxygen combustion mode, the ignition temperature, burnout temperature and apparent activation energy were improved.

With the continuous development of the computational fluid dynamics (CFD),using the method of computational fluid dynamics (CFD) to carry on the analysis of numerical simulation for turbulent combustion flow.Due to the low cost, short cycle.There is good practicability for Multiscale Problems.And it is very suitable for the study ${ }^{[10]}$ of burning or combustion gas flow problems. Therefore, this paper uses the method of FDS direct numerical simulation to simulate the movement of gas inside heating furnace under the cold .

\section{Construction of the oxy-fuel heating furnace model}

FDS software is developed by the American national institute of standards and technology (NISI).It is a computational fluid dynamics software which looks fluid movement of the fair as the main subject ${ }^{[11]}$. When the software carrying on combustion flow simulation, the equations include the continuity equation, the stress tensor equations, energy conservation equation, momentum equation and the gas component conservation equations.The five equations have the same characteristics of nonlinear, coupling, and closed forms.And they are the basic equation which can describe the gas flow and combustion in the oxy-fuel furnace ${ }^{[12-13]}$.In this paper,maked the designed industrial combustion furnace as a model,and using FDS software for modeling and numerical calculation.Under cold conditions,simulating the combustion gas movement of the furnace.

\subsection{Mathematical model:}

$$
\text { Continuity Equation: } \quad \frac{\partial \rho}{\partial t}+\nabla \cdot \rho \vec{u}=0
$$

Momentum Conservation Equation: $\frac{\partial(\rho \vec{u})}{\partial t}+\nabla \cdot \rho \vec{u} \vec{u}+\nabla p=\rho \vec{g}+f+\nabla \cdot \tau_{i j}$

Stress Tensor:

$$
\tau_{i j}=\mu\left(2 S_{i j}-\frac{2}{3} \delta_{i j}(\nabla \cdot \vec{u})\right)
$$

Energy Conservation Equation: $\quad \frac{\partial(\rho h)}{\partial t}+\nabla \cdot \rho \vec{u} h=\frac{D p}{D t}+q^{\prime \prime \prime}-q_{b}^{\prime \prime}+\varepsilon$

Ideal Gas Equation: $\quad P=\frac{\rho R T}{\bar{W}}$

\subsection{Physical model:}

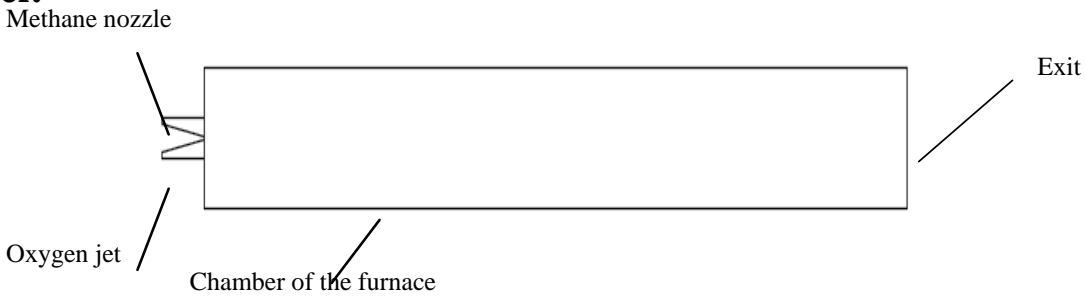

Fig.1. Schematic diagram of full oxygen heating furnace physical model

As shown in Fig.1,the oxy-fuel heating furnace has three main parts.It includes the nozzle, the furnace and the outlet.The upper nozzle provides with a fuel methane, and the lower nozzle is an oxygen nozzle. The designed size of the combustion furnace is long $2000 \mathrm{~mm}$, wide $200 \mathrm{~mm}$, high $200 \mathrm{~mm}$. The nozzle angle is 8 degrees, and two nozzle spacing is $10 \mathrm{~mm}$. Methane and oxygen from the nozzle launched into the chamber at a certain speed. Under the effect of the nozzle, both them increased disturbance and formed in the furnace reflux.As the same time,they dispersed throughout the furnace to achieve the state of dispersion. The flue gas is discharged from the rear exit. The calculation area is inside of the nozzle and the whole furnace.The article mainly analyses the gas 
movement in the furnace.

2.3 Grid independence test. In order to ensure accuracy, but also as far as possible to save computation time needed to test the independence of the grid. In this paper, the four grids: $300 * 30$ $* 40 * 30,400 * 40,500 * 50,600 * 50 * 60 * 60$, with the results shown in Fig.2.In the center of a cross-sectional analysis of $\mathrm{x}=28$ be in a position of the height of the center point velocity analysis, results $400 * 40 * 40$ obtained by simulation as a reference for comparison. From the figure can be found, along with an increase in the number of mesh, the simulation results gradually stabilized. Compared with the number of meshes $400 * 40 * 40$, the grid can not increase the number of very significant changes in the calculation of the results, so considering the computation time, the number of grid computing accuracy, the computer performance and other factors, select for simulation $400 * 40 * 40$.

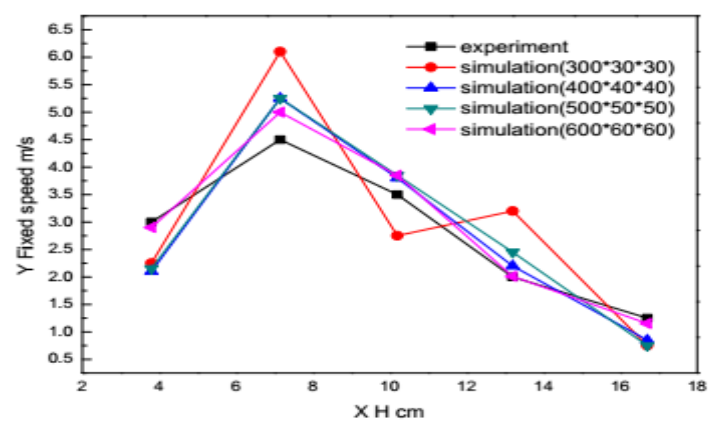

Fig.2. fixed speed and ratio of different grid numbers

\section{Numerical simulation of gas movement in the oxy-fuel heating furnace under cold state}

3.1 Numerical simulation of jet flow field under different nozzle velocity. This section uses FDS to simulate the cold state gas furnace movement at the $\mathrm{Z}=0.1 \mathrm{~m}$ cross section. The jet velocity of oxygen and methane respectively is $(20 \mathrm{~m} / \mathrm{s}, 10 \mathrm{~m} / \mathrm{s}),(50 \mathrm{~m} / \mathrm{s}, 25 \mathrm{~m} / \mathrm{s}),(100 \mathrm{~m} / \mathrm{s}, 50 \mathrm{~m} / \mathrm{s})$.Fig. 3 to 5 is the cloud chart of the gas flow field inside the furnace under the three nozzle gas velocity according to the reflux length.

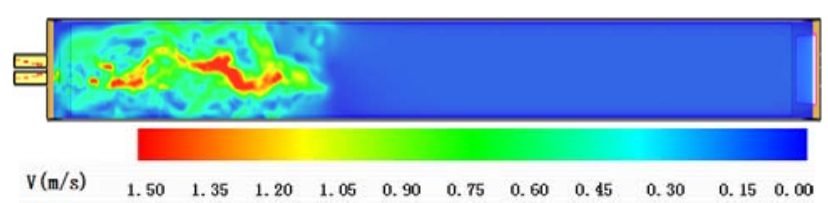

Fig.3. Cloud image of oxygen and methane nozzle with the speed of $(20 \mathrm{~m} / \mathrm{s}, 10 \mathrm{~m} / \mathrm{s})$

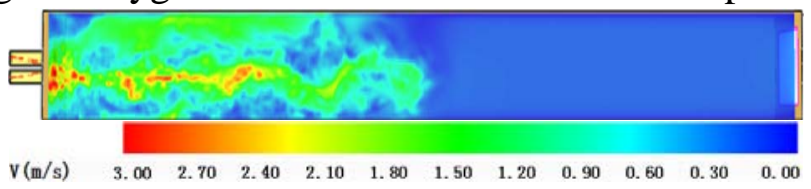

Fig.4. Cloud image of oxygen and methane nozzle with the speed of $(50 \mathrm{~m} / \mathrm{s}, 25 \mathrm{~m} / \mathrm{s})$

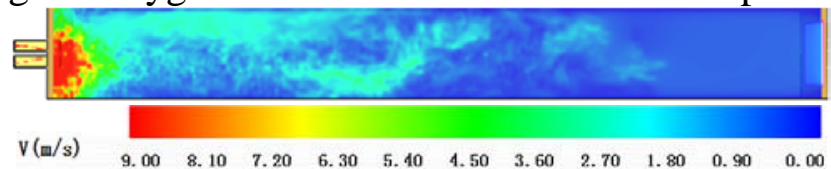

Fig.5. Cloud image of oxygen and methane nozzle with the speed of $(100 \mathrm{~m} / \mathrm{s}, 25 \mathrm{~m} / \mathrm{s})$

Results of simulation showed:when the oxygen and methane jet velocity is $(20 \mathrm{~m} / \mathrm{s}, 10 \mathrm{~m} / \mathrm{s})$, the combustion furnace maximum length is $0.62 \mathrm{~m}$ at $1.54 \mathrm{~s}$; when oxygen and methane jet velocity is $(50 \mathrm{~m} / \mathrm{s}, 25 \mathrm{~m} / \mathrm{s})$, the combustion furnace maximum length is $0.78 \mathrm{~m}$ at $1.39 \mathrm{~s} ;$ when oxygen and methane jet velocity is $(100 \mathrm{~m} / \mathrm{s}, 50 \mathrm{~m} / \mathrm{s})$, the combustion furnace maximum length is $0.97 \mathrm{~m}$ at 1.42s.The results of analysis show that the nozzle velocity is greater, the maximum reflux length of the gas in the furnace is longer,and the reflux area is larger. And with the increasing of the nozzle 
velocity, the velocity of forming maximum reflux length is also increased (The velocity of the three cases are $0.403 \mathrm{~m} / \mathrm{s}, 0.561 \mathrm{~m} / \mathrm{s}, 0.683 \mathrm{~m} / \mathrm{s}$ ). Comparison of above pictures also found that the velocity of the gas inside the furnace and the gas injected into the furnace have larger difference.This is because the gas has a different degree of spread diffusion whose direction is along with furnace length,furnace height and furnace width in the furnace,and resulting in the loss of gas velocity.This is consistent with the theory.

Fig.5-7 are velocity vector diagram of gas flow field in furnace,and the three kinds of oxygen and methane gas velocity are $(20 \mathrm{~m} / \mathrm{s}, 10 \mathrm{~m} / \mathrm{s}),(50 \mathrm{~m} / \mathrm{s}, 25 \mathrm{~m} / \mathrm{s}),(100 \mathrm{~m} / \mathrm{s}, 50 \mathrm{~m} / \mathrm{s})$ at the same time $(1 \mathrm{~s})$

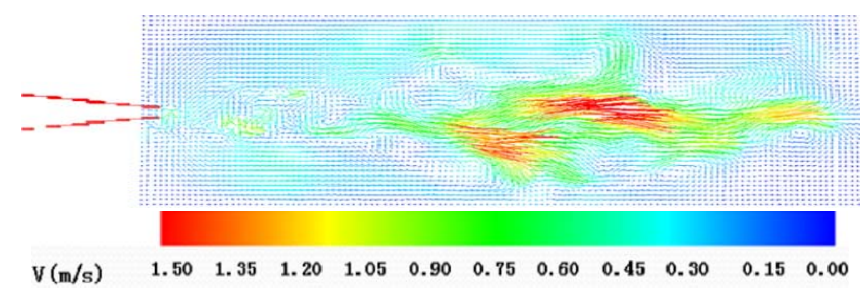

Fig.6. The flow field velocity vector of Methane and oxygen nozzle speed is $(20 \mathrm{~m} / \mathrm{s}, 10 \mathrm{~m} / \mathrm{s})$ at $1 \mathrm{~s}$

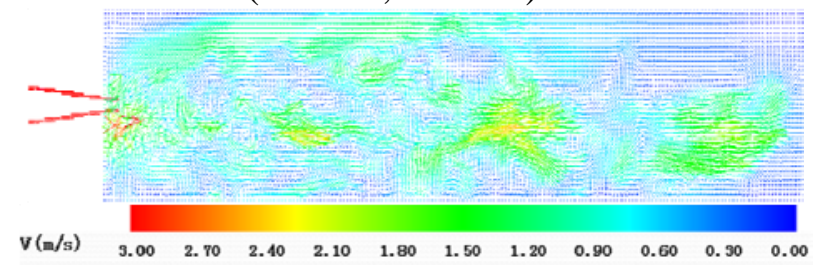

Fig.7. The flow field velocity vector of Methane and oxygen nozzle speed is $50 \mathrm{~m} / \mathrm{s}, 25 \mathrm{~m} / \mathrm{s}$ ) at $1 \mathrm{~s}$

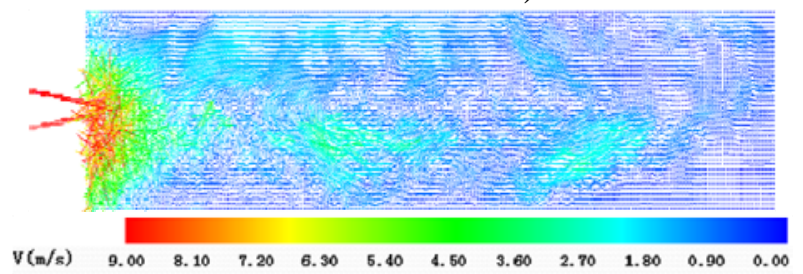

Fig.8. The flow field velocity vector of Methane and oxygen nozzle speed is $(100 \mathrm{~m} / \mathrm{s}, 50 \mathrm{~m} / \mathrm{s})$ at $1 \mathrm{~s}$

Fig.6 to 8 results of simulation showed: when oxygen and methane jet velocity is $(20 \mathrm{~m} / \mathrm{s}$, $10 \mathrm{~m} / \mathrm{s}$ )and time of simulation is $1 \mathrm{~s}$, the spread length of the gas in the furnace is $0.58 \mathrm{~m}$;when oxygen and methane jet velocity is $(50 \mathrm{~m} / \mathrm{s}, 25 \mathrm{~m} / \mathrm{s})$, and time of simulation is $1 \mathrm{~s}$, the spread length of gas in the furnace is $0.88 \mathrm{~m}$; when oxygen and methane jet velocity is $(100 \mathrm{~m} / \mathrm{s}, 50 \mathrm{~m} / \mathrm{s})$, and time of simulation is $1 \mathrm{~s}$, the spread length of gas in the furnace is $1.16 \mathrm{~m}$. And compared with the three charts at the same time, found that the speed of nozzle is greater,the vortex formed in the furnace is more,and the number of vorticity is greater.It is conducive to form the internal diffusion combustion conditions. There is certain directive significance for the gas nozzle speed design of the oxy-fuel heating furnace.

3.2 Analysis of the vortex at Cente rsection of the furnace width of the $\mathrm{Z}=\mathbf{0 . 1 \mathrm { m }}$. Vorticity represents curl of the fluid velocity vector.The study of the vorticity field in the furnace can be better informed gas spread in furnace.This section mainly research the different nozzle velocity and the vorticity of section $(Z=0.1 \mathrm{~m})$,selecting velocity of cross section at the $4.5 \mathrm{~s}$ moment,and put the data into Tecplot to carry on vorticity processing(the calculating formulathe of velocity and vorticity is $w z=d d x(v)-d d y(u), u$ is the speed alonged with furnace length $x, v$ is the speed alonged with furnace high $y$.) The $X$ direction selects the specific range $(0-100 \mathrm{~cm})$ to carry on analysis.(From the computing data to analyse, the vorticity of the heating furnace mainly concentrated in the specific range which is 0 to $100 \mathrm{~cm}$ of long furnace),Fig.9 to 11 are the the contour of vorticity at $\mathrm{Z}=0.1 \mathrm{~m}$ 
section, and the nozzle velocity of methane and oxygen respectively is $(20 \mathrm{~m} / \mathrm{s}, 10 \mathrm{~m} / \mathrm{s})(50 \mathrm{~m} / \mathrm{s}$, $25 \mathrm{~m} / \mathrm{s}),(80 \mathrm{~m} / \mathrm{s} 40 \mathrm{~m} / \mathrm{s})$.

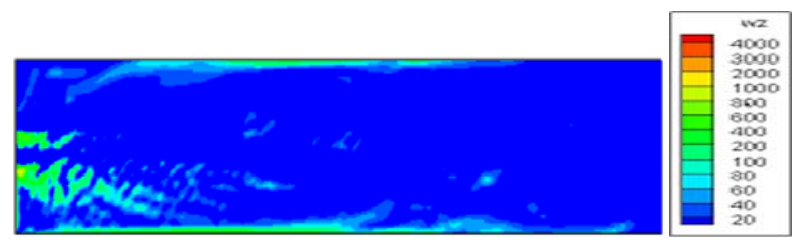

Fig.9. Vortex cloud image under the velocity is $(20 \mathrm{~m} / \mathrm{s}, 10 \mathrm{~m} / \mathrm{s})$ and at the furnace width $\mathrm{Z}=0.1 \mathrm{~m}$ section

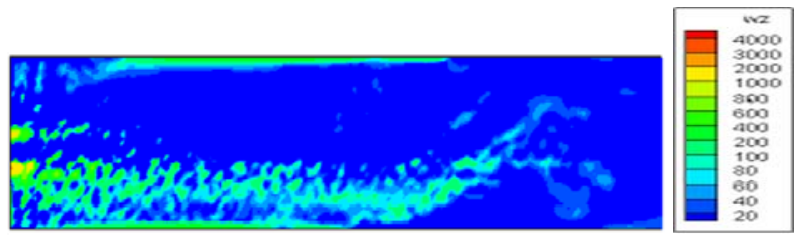

Fig.10. Vortex cloud image under the velocity is $(50 \mathrm{~m} / \mathrm{s}, 25 \mathrm{~m} / \mathrm{s})$ and at the furnace width $\mathrm{Z}=0.1 \mathrm{~m}$ section

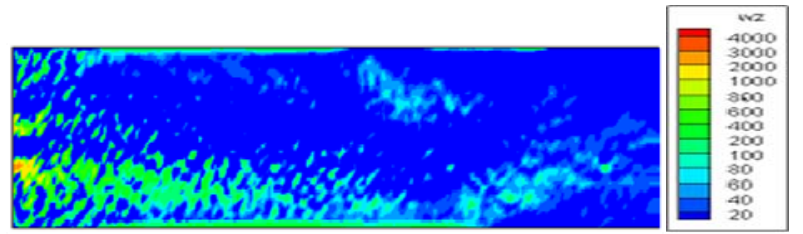

Fig.11. Vortex cloud image under the velocity is $(80 \mathrm{~m} / \mathrm{s}, 40 \mathrm{~m} / \mathrm{s})$ and at the furnace width $\mathrm{Z}=0.1 \mathrm{~m}$ section

Compared with the Fig.9 to 11 can be found that the vorticity and the range of generated vorticity in Fig 10 and Fig11 is far greater than the situation in Fig 9.The analysis of reasons: the nozzle velocity of oxygen and methane is $(20 \mathrm{~m} / \mathrm{s}, 10 \mathrm{~m} / \mathrm{s})$ in Fig 6.36, and compared to $(50 \mathrm{~m} / \mathrm{s}$, $25 \mathrm{~m} / \mathrm{s})$ of Fig 6.37 and $(80 \mathrm{~m} / \mathrm{s}, 40 \mathrm{~m} / \mathrm{s})$ Fig 6.38,it is smaller.It can prove that the nozzle velocity is greater,the vortex of gas formed in the furnace is also greater,and the range of vorticity are also wider.Therefore, it is more conducive for the diffusion of the gas in the furnace.Compared with the three figures can find that Vorticity mainly exists in the nozzle,near the columnar jet which the nozzle produced and the edge of the upper and lower furnace walls. The analysis of reasons:because the vorticity represents the rotation of the fluid velocity vector.At nozzle and a columnar jet near the nozzle,gas velocity is greater,and the intensity of turbulence is drastic,so the generated vorticity is larger.However, for the upper and lower furnace walls,after the gas spread to the wall under the function of a nozzle,and collision with the wall.Found that the direction of gas velocity has obvious change in here.Therefore, a certain amount of vortex formed. And the size of vortex reflects the degree of fluctuation of speed.Compared with the three figures also found that with the increasing of furnace length about $x$ direction,the value of vorticity reduced gradually.This is because the gas velocity decreases constantly in the length direction the furnace, reduced speed also means to the eddy dissipation along with the direction of the furnace length.So the vorticity decreases constantly in the direction of furnace length.The analysis of vorticity field shows the result of velocity field analysis.It is that if the nozzle velocity is bigger,it will be more favorable for the diffusion of gas in the furnace.

\section{Conclusions}

(1) Carrying on the test of the grid independence, it can be concluded that the number of internal grids set up $400 * 40 * 40$ is more reasonable in this model. It not only saves the time of the simulation calculation, but also obtains the relatively reasonable calculation result.

(2) The velocity field of $\mathrm{Z}=0.1 \mathrm{~m}$ cross section is analyzed and the results showed that the greater 
the gas velocity of the nozzle, the longer the maximum reflux length of gas in the furnace, the greater the reflux zone formed in the furnace.

formed in the furnace is greater.

(3) By analyzing vorticity of $\mathrm{Z}=0.1 \mathrm{~m}$ cross section, compared the experimental results with the simulation results of flow field inside the oxy-fuel heating furnace, found that at the same time, the speed is greater, the vorticity generated within the furnace is more.It is more conducive to the diffusion of the gas in the furnace, and achieving MILD combustion.

\section{Acknowledgements}

This work was financially supported by the National Natural Science Foundation of China (51464014), the Major State Basic Research Development Program of China.

\section{Reference}

[1] Toftegaard. M.B , BRIX.J , JENSEN.P.A , et al. Oxy-fuel combustion of solid fuels . Progress in Energy and Combustion Science, 2010 , 36(5) :581-625.

[2] Yamada. T, Tamura .M, Ffjimori.T, et al. Test results of oxy- fuel combustion and Outline of demonstration project in Australia [J]. Challenges of Power Engineering and Environment, 2007, (2) :756-761.

[3] Strom.berg.L, Ljndgrena.G, Jacoby.J, et al. Update on Vattenfall's 30 MWth Oxy-fuel Pilot Plant in Schwarze Pumpe[J] .Greenhouse Gas Control Technologies ,2009,1(1) :581-589.

[4] R Eichler. Recent Developments in Oxy-fuel Technology for Heating Furnaces[J]. Proc. IFRF's 25th ToTeM, Stockholm, Sweden, 2003: 2 7.

[5] Kim.H.K, Kim.Y. Studies on combustion characteristics and flame length of Turbulentoxy-fuelflames[J] . Energy\&Fuels, 2007, 21(3):1459-1467.

[6] Nozaki.T, Takano.J, Kiga.T, et al. Analysis of the flame formed during oxidation of Pulverized coal by an 02 - CO2 mixture[J]. Energy,22(2-3):199-205.

[7] Till marc Numerical simulation of oxygen-enriched combustion in industrial processes[J]. Computational Fluid Dynamics, 2003,(3):42-52.

[8] Xiao-hong HUANG,Zhao-hui LIU,Jing-Zhang LIU,et al. Experimental investigation on flame characteristics of pulverized coal combustion under 02/CO2 atmosphere[J]. Journal of Engineering Thermophysics,2009,30 ( 7 ):1245-1248. (In Chinese)

[9] Le WU,Ming-hou XU,Sheng-fu WANG,et al. Study of different densities pulverized coal combustion characteristics under 02/CO2 atmosphere[J]. Journal of Engineering Thermophysics, 2010,31 (10):1789-1792. (In Chinese)

[10]Yu-da HUANG,Xia WEI,Zhao-guo SUN,et al. Numerical simulation research of turbulent combustion flow field based on parallel computing[J]. Science Technology and Engineering, 2012,12 (17) : 4192-4196. (In Chinese)

[11]Zhe XIN,Shun-xi WANG,Feng YUN,et al. Numerical analysis on spreading laws of grassland fire based on fire dynamics simulator(FDS). Transactions of the Chinese Society of Agricultural Engineering,2013,29(11):156-163. (In Chinese)

[12]Jun LIU,Min LIU,Hui-qiang ZHI,et al. FDS fire dynamics simulator basic theory and application tips[J]. Safety,2006(1):6-13. (In Chinese)

[13]Zai-zhen LI. Numerical analysis about the Shangjie highway of tunnel fire based on FDS[D].Xi An:2011.(In Chinese) 